Case Report

DOI: http://dx.doi.org/10.18203/issn.2454-5929.ijohns20174348

\title{
A large sinonasal schwannoma: a rare entity
}

\section{Manwinder Singh*, Sanjeev Bhagat, Dinesh Kumar Sharma, Rabia Monga, Nitin Chhabra}

Department of ENT, Government Medical College, Patiala, India

Received: 14 July 2017

Accepted: 30 August 2017

\author{
*Correspondence: \\ Dr. Manwinder Singh, \\ E-mail: doctormanvinder@gmail.com
}

Copyright: () the author(s), publisher and licensee Medip Academy. This is an open-access article distributed under the terms of the Creative Commons Attribution Non-Commercial License, which permits unrestricted non-commercial use, distribution, and reproduction in any medium, provided the original work is properly cited.

\begin{abstract}
Schwannoma is a rare neoplasm of nose and PNS which develops from Schwann's cells of neural sheath and most are benign and encapsulated and amenable to surgical excision. The aim of this write-up is to report a rare case of schwannoma of nose and PNS. We report a case of 40 year old female, a housewife, presented in ENT OPD with complaints of nasal obstruction on right side, post nasal drip and headache. On diagnostic nasal endoscopy, there was a polypoidal mass coming from the middle meatus which was pushing the medial turbinate medially. NCCT and MRI of nose and PNS showed soft tissue density mass involving right ethmoidal air cells, maxillary sinus and bilateral sphenoid sinuses and eroding the lateral wall of right maxillary sinus reaching upto infratemporal fossa, superiorly mass was seen eroding the inferior wall of right orbit. The tumour was removed endoscopically piecemeal and sent for histopathology which showed it to be a schwannoma. The conclusion of the finding was schwannoma involving nasal cavity, maxillary sinus and sphenoid sinus eroded the lateral wall of maxillary sinus going into infratemporal fossa and floor of the orbit. Schwannoma should also be kept as a possibility in the differential diagnosis of tumors of nose and PNS.
\end{abstract}

Keywords: Schwannoma, Maxillary sinus, Endoscope

\section{INTRODUCTION}

Schwannoma is a benign slow-growing neoplasm composed entirely of nerve-supporting cells without neuronal elements. Although $25-45 \%$ of schwannoma arise in the head and neck region, only $4 \%$ of schwannomas occur in the sinonasal cavity. ${ }^{1-3}$ The neoplasm develops from Schwann's cells of neural sheath and most are benign and encapsulated and amenable to surgical excision.

In the paranasal sinuses, they can either arise from the ophthalmic or maxillary divisions of the trigeminal nerve or from the branches of the autonomic nervous system. The maxillary and ethmoid sinuses are more commonly involved. Primary involvement of the sphenoid sinus with three reported cases and frontal sinus is extremely rare. ${ }^{4-7}$
We report a rare case of large schwannoma involving nasal cavity, maxillary sinus and sphenoid sinus and eroding the lateral wall of maxillary sinus going into infratemporal fossa and floor of the orbit. The tumour was removed by endoscopic approach.

\section{CASE REPORT}

A 40 year old female, a housewife, who presented to ENT OPD with complaints of nasal obstruction on right side, post nasal drip and headache for 1 year.

Patient started complaining of right sided nasal obstruction one year back, which was insidious in onset, progressive and more during night time. Patient also had history of post nasal drip for one year requiring constant throat clearing. She also complained of headache in bilateral temporal region, which was dull in character and 
temporarily relieved on taking medication. No history of preceeding vomiting or photophobia was recorded. Patient also gave history of hyposmia on being asked a direct question.

There was no history of excessive sneezing, bleeding from nose, diplopia facial numbness, change of voice, visual disturbance or any ear symptoms. On clinical examination nasal dorsum was normal. Infraorbital margins were regular. The eyeball movements were normal and visual acquity was normal. All the cranial nerve examination was normal. On anterior rhinoscopy the septum was deviated to left and there was inferior turbinate hypertrophy on the right side.

On diagnostic nasal endoscopy, there was inferior turbinate hypertrophy on right side. There was a polypoidal mass coming from the middle meatus which was pushing the medial turbinate medially and nasal septum towards the left. There was some oozing of blood from the mass on probing and the probe could not be passed laterally. On left side the septum was deviated and touching the inferior turbinate. Bulla ethmoidalis was oedematous and small polyp was present in the middle meatus on left side.

NCCT of nose and PNS showed soft tissue density mass involving right ethmoidal air cells, maxillary sinus and bilateral sphenoid sinuses. Mass was also involving the nasal septum deviating it to left side. Mass was extending beyond the right maxillary sinus and eroding the lateral wall of right maxillary sinus reaching upto infratemporal fossa, superiorly mass was seen eroding the inferior wall of right orbit and extending into the orbit as shown in the CT pictures (Figures 1 and 2).

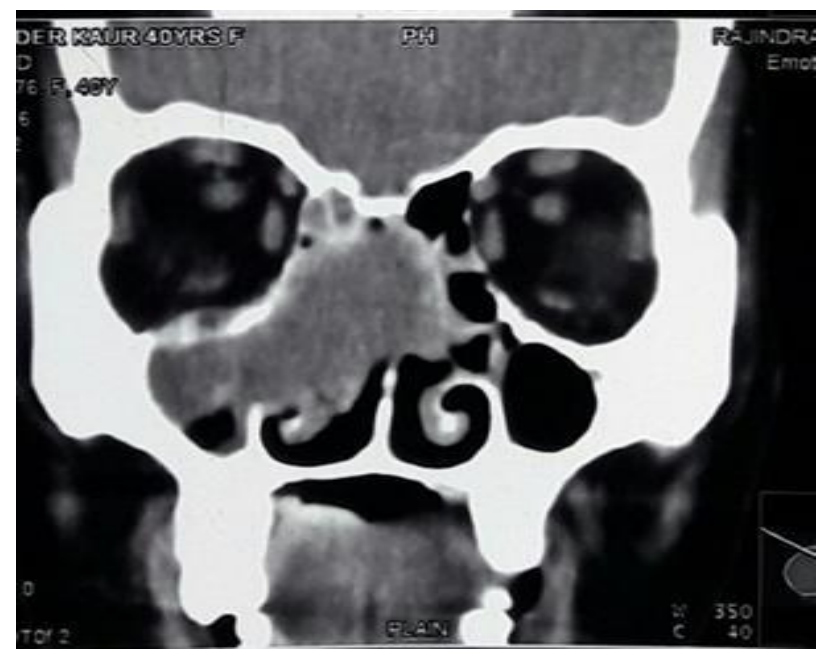

Figure 1: NCCT nose and PNS coronal view showing tumour involving ethmoid and maxillary sinuses on right side.

MRI was done, T2W images showed a heterogenous mass involving right ethmoid, maxillary and bilateral sphenoid sinuses and extending beyond the right maxillary sinus eroding the lateral wall and going to the infratemporal fossa. Superiorly mass was seen eroding the inferior wall of right orbit and extending into the orbit as shown in the MRI pictures (Figures 3 and 4). No intracranial extension was seen.

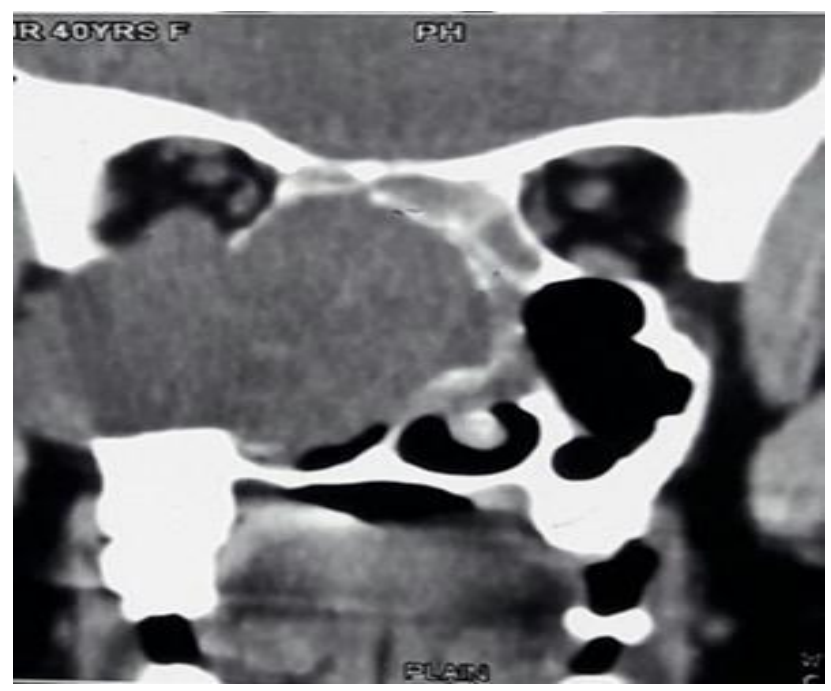

Figure 2: NCCT nose and PNS coronal view showing tumour involving ethmoid, maxillary sinuses and eroding the lateral wall of maxillary sinus reaching upto infratemporal fossa, superiorly eroding the inferior wall of orbit on right side.

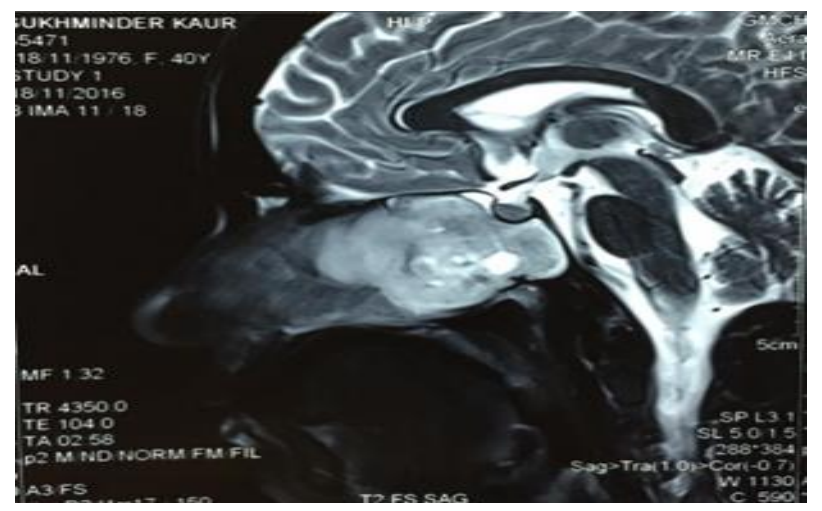

Figure 3: T2W MRI saggital view showing tumour with no intracranial extension.

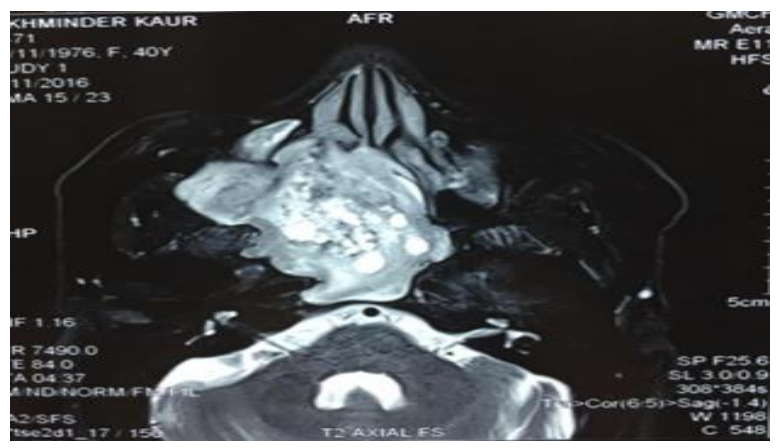

Figure 4: T2W MRI axial view showing extensions of various extensions of tumor. 
Biopsy was taken endoscopically under local anaesthesia and sent for was done under general anaesthesia which again came out to be inflammatory polyp.

A transnasal endoscopic approach was undertaken to excise the tumor under general anaesthesia. A piecemeal removal of the mass was done and haemostasis achieved. Mass was soft and friable and came out easily without much bleeding. The mass removed was sent for histopathological examination. Post-operative period was uneventful.

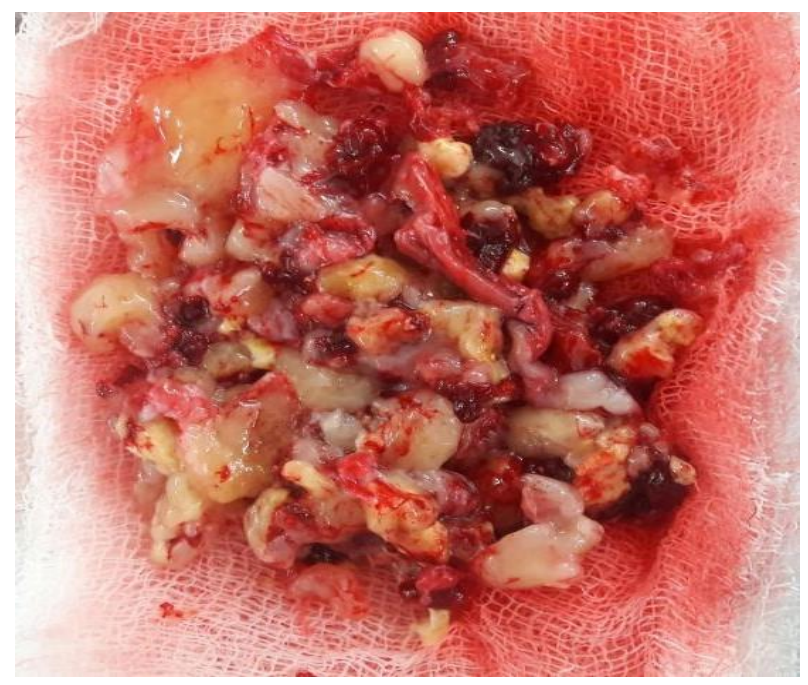

Figure 5: Tumour removed piecemeal endoscopically.

Histopathological examination revealed ciliated columnar respiratory epithelium overlying the tumor composed of spindle shaped wavy cells with vesicular indented nuclei arranged in fascicles in a pallisading pattern suggestive of Antoni A pattern along with oedematous Antoni B pattern, proliferating congested vascular channels with hyaline vascular cuffs, bizarre cells, foci of myxoid and cystic degeneration, areas of collagenization along with lymphocytes, haemosiderin laden macrophages and mast cells. Hence, the tumour was diagnosed as schwannoma.

On follow-up after 3 months, the patient was asymptomatic and there was no evidence of residual tumour on nasal endoscopy.

\section{DISCUSSION}

Schwannomas are nerve sheath tumours that arise from Schwann cells that are derived from the neuroectoderm. For many years, controversy has existed concerning the nomenclature to be used in the classification of these lesions. The solitary schwannoma has also been called neurilemoma, neurilemmoma, neurolemmoma and neurinoma. Schwann cell tumours occur only infrequently in the nasal cavity and paranasal sinuses. Only a relatively small number of Schwann cell tumours involving the alae nasi, nasal cavity, ethmoid region, maxilla, frontal sinus and sphenoid sinus have been reported in the literature. In most reports, only one or two cases are described or mentioned. Conley and Janecka reviewed 90 patients with Schwann cell neoplasms of the head and neck; of these, three lesions were found in the nose, three in the maxilla, and one each in the nasopharynx and fronto-ethmoid area. ${ }^{8}$ In a review of 152 "benign and malignant neurilem- momas" of the head and neck, Kragh et al described five in the nasal fossa and antral regions. ${ }^{9}$ Kautzky et al in 1989 have reported a schwannoma of the frontoethmoid complex that recurred after 7 years and had malignant transformation. ${ }^{7}$

The symptoms of schwannoma involving the paranasal sinuses vary according to site, nerve of origin and/or compression of adjacent nerves. Epistaxis is related to ethmold sinus or nasal fossa and pain to maxillary sinus involvement. ${ }^{10}$ Other symptoms being facial swelling, hypoaesthesia, nasal obstruction, mucopurulent rhinorrhoea, exophthalmos and hyposmia. ${ }^{6}$ Lesions can also present as a nasal polyp when clinically it has to be differentiated from angiofibroma and fibrotic nasal polyp. ${ }^{11}$ In sphenold sinus schwannoma diplopia (cranial nerves involvement) and deep retroorbital and/or occipital, frontal and bitemporal pain have been reported with the possibility of hypopitutarism with posterior extension to the hypophysis. ${ }^{3-5}$ Tumour in our case was involving the sphenoid sinus and patient complained of bitemporal pain.

Differential diagnosis of schwannoma of the paranasal sinuses should include mucocele, ossifying fibroma, ameloblastoma, dentigerous cyst and other mesenchymal tumors and solitary bone cyst. ${ }^{12}$

CT scan or MRI of the paranasal sinuses is useful in planning the surgical treatment. The characteristic lesion is a well-defined mass associated with thinning of the surrounding bone by the slow growing mass. ${ }^{6} \mathrm{CT}$ scan is helpful in assessing the tumor size, location and erosion of bony surfaces. ${ }^{13,14} \mathrm{MR}$ imaging is used in lntracranial or Intraorbital extensions and delineates the neoplasm from retained secretions or inflammatory changes. ${ }^{15}$ Benign schwannomas can erode bone by pressure.In our case the tumour was eroding lateral wall of maxillary sinus and going into infratemporal fossa. Hence, bony erosion is not a criterion for malignancy. The diagnosis must be confirmed by histological examination of tissue specimen. The S 100 immunoperoxidase stain for schwann cell origin in the lesion helps clinch the diagnosis, though the characteristic histopathologlcal findings are sufficient. ${ }^{16}$

Treatment of benign schwannomas is often limited to debulking and close follow up, but surgical excision is encouraged if anatomic structures can be preserved. ${ }^{17}$

Endoscopic approach has enabled us to remove the tumor in piecemeal fashion unlike the lateral rhinotomy where enmass removal of the tumor might have been possible. 
However, we consider the endoscopic approach more appropriate, keeping in view the cosmetic aspect of the lateral rhinotomy incision.

In the above case report, it is difficult to speculate the exact nerve of origin of the schwannoma. But it can be said that one of the branches of the ophthalmic or maxillary divisions of the trigeminal nerve is the possible site.

\section{CONCLUSION}

We report a rare case of large schwannoma involving nasal cavity, maxillary sinus and sphenoid sinus and eroding the lateral wall of maxillary sinus going into infratemporal fossa and floor of the orbit. Although sinonasal schwannomas are rare and their imaging findings are rather nonspecific, CT and MR imaging studies are helpful for preoperative diagnosis and surgical planning in patients with schwannoma of the sinonasal cavity.

Funding: No funding sources Conflict of interest: None declared

Ethical approval: Not required

\section{REFERENCES}

1. Batsakis JG. Tumors of the peripheral nervous system. Williams and Wilkins Balumore. 2nd edition. 1979: 313-3.

2. Wilson JA, Mclntyre MA, Mclaren K, Von Haccje NP, Maran AGD. Nerve sheath tumors of the head and neck. Ear, Nose Throat J. 1988;67:103-10.

3. Hillstrom RP, Zarbo RJ, Jacobs JR. Nerve sheath tumors of the paranasal sinuses: electron microscopy and histopathologic diagnosis. Otolaryngol Head Neck Surg. 1990;102:257-63.

4. Calcaterra TC, Rich R, Ward PW. Neurilemmoma of the sphenoid sinus. Arch Otolaryngol Head Neck Surg. 1974; 100:383-5.

5. Srinivasan V, Deans JA, Nicol A. Sphenoid sinus schwannoma treated by endoscopic excision. J Laryngol Otol. 1999;113(5):466-8.
6. Shugar MA, Montogomery WW, Reardon EJ . Management of paranasal sinus schwannomas. Ann Otol Rhinol Laryngol. 1982;91:65-9.

7. Kautzky M, Schenk P. Schwannoma of the nose and paranasal sinuses. Laryngorhinootologie. 1989;68(10):547-51.

8. Conley J, Janecka P. Neurilemmoma of the head and neck. Trans Am Acad Ophthalmol Otolaryngol. 1975;80:59-464.

9. Kragh LV, Soule EH, Masson K. Benign and malignant neurilemmomas of the head and neck. Surg Gynecol Obstetrics. 1960;111:211-8.

10. Robitaille Y, Seemayer TA, El Deiry A. Peripheral nerve tu- mors involving paranasal sinuses: A case report and review of the literature. Cancer. 1975;35:1254-8.

11. Kaufmann SM, Conrad LP. Schwannoma presenting as a nasal polyp. Laryngoscope. 1976;86:595- 7.

12. Weber AC, Montgomery WW. Neurilemmoma ol maxillary antrum. Annls Otol Rhinol Laryngol. 1978;87:436-7.

13. Younis DT, Gross CW, Lazar RH. Schwannomas of the paranasal sinuses Case report and clinicopathological analysis. Arch Otolaryngol Head Neck Surg. 1991;117:677-80.

14. Donnelly MJ, Al Sider MH, Blayney AW. Benign nasal schwannoma. J Laryngol Otol. 1992;106:1011-5.

15. Dublin $\mathrm{AB}$, Dedo $\mathrm{HH}$, Bndger WH. Intranasal schwannoma Magnetic resonance and computed tomography appearance. Am J Otolaryngol. 1995;16:251-4.

16. Hazarika P, Nayak DR, Pujary K, Rao L. Schwannomas of nose and paranasal sinuses. Indian J Otolaryngol Head Neck Surgery. 2003;55(1):34-8.

17. Younis RT, Gross CW, Lazar RH. Schwannomas of Paranasal Sinuses. Arch Otolaryngol Head Neck Surg. 1991;117:677-80.

Cite this article as: Singh $M$, Bhagat $S$, Sharma DK, Monga R, Chhabra N. A large sinonasal schwannoma: a rare entity. Int J Otorhinolaryngol Head Neck Surg 2017;3:1126-9. 